https://doi.org/10.11646/bde.43.1.4

\title{
Advances and challenges in bryophyte biology after 50 years of International Association of Bryologists
}

\author{
MICHAEL STECH ${ }^{1,2}$, PAULO E.A.S. CÂMARA ${ }^{3}$, RAFAEL MEDINA ${ }^{4} \&$ JESÚS MUÑOZ \\ ${ }^{I}$ Naturalis Biodiversity Center, P.O. Box 9517, 2300 RA Leiden, Netherlands; \\ ${ }^{2}$ Leiden University, Leiden, Netherlands; \\ ”-michael.stech@naturalis.nl; @ https://orcid.org/0000-0001-9804-0120 \\ ${ }^{3}$ Departamento de Botânica, Universidade de Brasília, Brazil UnB; \\ इ" paducamara@gmail.com; 으ttps://orcid.org/0000-0002-3944-996X \\ ${ }^{4}$ Departamento de Biodiversidad, Ecología y Evolución, Universidad Complutense de Madrid, C/ José Antonio Novais, 12, 28040 \\ Madrid, Spain;

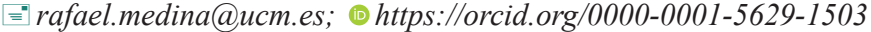 \\ ${ }^{5}$ Real Jardin Botánico (CSIC), Plaza de Murillo, 2, 28014 Madrid, Spain \\ "”jmunoz@rjb.csic.es; ○ https://orcid.org/0000-0002-9266-2268
}

Research on bryophyte biology has made exciting advances during the last 10 to 15 years since the publications of Goffinet \& Shaw (2008) and Frey \& Stech (2009) that summarized the knowledge of the field. New fossils provided insights into past bryophyte diversity and integrative taxonomic approaches combine the ever increasing molecular data with thorough assessments of morphology and anatomy. Patterns of speciation, diversity at population level and geographic distributions are becoming better understood, and the interactions of bryophytes with their biotic and abiotic environment are increasingly being revealed. Nevertheless, important knowledge gaps remain, and anthropogenic threats such as habitat alterations and global climate change on bryophyte diversity increase the urgency of further research.

To mark the $50^{\text {th }}$ anniversary of the International Association of Bryologists (IAB), this special issue of Bryophyte Diversity and Evolution presents a collection of 15 scientific papers that summarize the current state of knowledge, highlight new insights, and point out future directions of diverse aspects of bryophyte biology. The scientific papers are preceded by a flashback on 50 years of IAB activities pivotal to foster bryological knowledge, namely the organization of meetings, dissemination of bryological news, publication of scientific data, and awarding of prizes and grants (Gradstein 2021).

The first two scientific papers go back in evolutionary time and provide checklists of the fossil records of liverworts (Feldberg et al. 2021) and mosses (Ignatov \& Maslova 2021), along with a discussion on the suitability of fossils as age constraints on molecular phylogenetic reconstructions. Numbers of fossils described have increased considerably in both liverworts and mosses, in particular from amber, but as discussed in both contributions, the identification of many older fossils in particular remains ambiguous. Nevertheless, the authors list several fossils suitable for calibrating molecular trees, which could be used for future evolutionary inferences from molecular data.

Discussing both the fossil and extant diversity, Bell et al. (2021) review the current knowledge on the phylogenetically isolated lineage of the "hair-cap mosses", class Polytrichopsida. They conclude that molecular phylogenetic analyses were able to resolve generic circumscriptions and relationships with fairly high confidence, and that the molecular relationships are, with few exceptions, supported by morphological characters and in line with the most developed classification from before the molecular era. However, future work is needed, ranging from taxonomic revisions to obtaining annotated genomes for selected species as a basis for physiological, developmental and comparative genomic studies. The latter aspect leads to the following contribution by Dong \& Liu (2021), who compare mitochondrial genome diversity and evolution between liverworts, mosses, and hornworts. Bryophyte mitogenomes show lineagespecific characteristics and a conserved structure that might be maintained by different evolutionary mechanisms among these lineages. The authors acknowledge that high-throughput sequencing technologies offer new possibilities for in-depth studies of mitogenome evolution in bryophytes, including patterns and mechanisms of intron losses and gains, and the impact of RNA editing on phylogenetic reconstructions.

Leaving the field of macro-evolution and phylogeny, several papers of the special issue address karyology and biological processes involved in speciation in bryophytes. Sousa \& Renner (2021) compare different protocols and 
provide step-by-step instructions to obtain meiotic or mitotic chromosome spreads from gametophytic (phyllids, antheridia) and sporophytic tissue of liverworts, tested on a number of species. These instructions should facilitate future cytogenetic studies in bryophytes. Carey et al. (2021) highlight the novel insights into genome evolution that can be gained by studying haploid $\mathrm{U}$ and $\mathrm{V}$ sex chromosomes in bryophytes. Although many of the processes shaping the evolution of haploid and diploid sex chromosomes are the same, the authors' observations demonstrate the potential for evolutionary genomic analyses of UV sex chromosome systems, combined with natural history studies, to understand how genetic conflict shapes sex chromosome gene content. Patel et al. (2021) reflect on karyotype diversity as a factor critical to catalyzing change in plant evolution. According to the authors, allopolyploidy receives more attention, while the prevalence and significance of autopolyploidy and aneuploidy in bryophytes is yet little understood. Based on comparative analysis of published ploidy levels in moss species, they conclude that cytological diversity likely underlies yet undescribed species diversity and emphasize the need of intensive karyological sampling to discover this diversity. Ostendorf et al. (2021) zoom in on the processes of polyploidization in the moss family Funariaceae. Based on phylogenetic and phylogenomic inferences from the model species Physcomitrium (Physcomitrella) patens (Hedwig 1801: 20) Mitten (1851:363) and related species, they conclude that polyploidization, likely via hybridization, indeed gives rise to new species within the Funariaceae. Furthermore, the study highlights the potential impact of polyploidization on spore size and sporophyte architecture in the family. Expanding this topic to bryophytes in general again, Sawangproh \& Cronberg (2021) conclude that hybridization is an important evolutionary phenomenon among bryophytes. Although the current molecular approaches support the prevalence of allopolyploidy, the authors, in line with Patel et al. (2021), anticipate that homoploid hybridization is more frequent than reported so far, and suggest directions for future studies of hybrid speciation among bryophytes.

The special volume continues with two contributions dealing with specific geographic aspects of bryophyte diversity and evolution. Patiño \& Vanderpoorten (2021) provide an updated account on the impact of bryology in island biogeography, in the framework of the 50 most fundamental questions for present and future island biology research identified by Patiño et al. (2017). According to their assessment, only about $50 \%$ of the key current questions in island biogeography have been addressed for bryophytes, and especially species and community phylogenetics, biotic interactions, and invasion biology of island bryophytes need to be further explored. Câmara et al. (2021) review the current state and discuss future directions of Antarctic bryophyte research, following up on a similar account on Arctic bryophytes (Lewis et al. 2017). While molecular data provide new insights into species delimitations, population diversity, origin of bipolar distribution patterns and dispersal pathways to and within Antarctica, especially liverworts are understudied and the impact of climate change on Antarctic bryophytes remains to be assessed.

Ecological topics are addressed by two following papers of the special issue. Stanton \& Coe (2021) discuss three core aspects of functional ecological traits in bryophytes, namely dynamic water content (including poikilohydry and desiccation tolerance), multiple scales of interaction with the environment, and reproduction and life history. The authors furthermore highlight how bryophytes influence ecosystem processes, including primary productivity, nutrient cycling, hydrology, and ecological interactions with other species, and indicate knowledge gaps for future studies. Vitt \& House (2021) emphasize the role of bryophytes as key indicators of ecosystem functioning and structure of northern peatlands, focusing on mechanisms of resistance to decay in ecological groups that are dominant in bogs and poor fens versus rich fens. Furthermore, the authors point out the importance of bryophyte species and their abundances across different gradients as indicators for classifying wetland site-types.

Hornworts, the smallest, yet highly characteristic bryophyte lineage, have so far only been addressed in this special issue in the contributions on mitogenomes (Dong \& Liu 2021) and hybridization (with no record of hybridization in hornworts found; Sawangproh \& Cronberg 2021). The second last paper by Henry et al. (2021), in contrast, specifically focuses on the biochemistry and development of the unique placenta of hornworts. After the recent study on cell wall polymers in the placenta of the liverwort Marchantia Linnaeus (1753: 1137-1138) by Henry et al. (2020), the present study of two species of the hornwort genus Phaeoceros Proskauer (1951:346-347) allows the first detailed comparison of placental cell wall organization in bryophytes.

Last but not least, Pressel et al. (2021) address interactions between bryophytes and fungi in their review on mycorrhizal-like associations. They highlight that early divergent liverwort clades and some hornworts engage with a wider repertoire of fungal symbionts than previously thought, and that Mucoromycotina symbionts, together with Glomeromycota, are widespread in thalloid liverworts and hornworts, confirming that these associations are mycorrhizal-like in liverworts. Furthermore, the study reports a higher diversity of ascomycete symbionts of leafy liverworts than previously known.

The abovementioned papers clearly demonstrate the progress that has been made in diverse fields of bryophyte biology, while at the same time pointing out important knowledge gaps. We hope that this special issue of Bryophyte 
Diversity and Evolution will stimulate, and serve as a reference for, future research that aims to fill these gaps and further advance our understanding of the fascinating world of bryophytes.

\section{Acknowledgements}

We are grateful to Bernard Goffinet for comments on the editorial. Contributors to the IAB $50^{\text {th }}$ anniversary special issue were invited by Bernard Goffinet, Matt von Konrat and Dietmar Quandt, whose support during the process of assembling the special issue is gratefully acknowledged. Furthermore, we sincerely thank all reviewers as well as ZhiQiang Zhang and the BDE production staff for their help to make the special issue possible.

\section{References}

Bell, N., Kariyawasam, I., Flores, J. \& Hyvönen, J. (2021) The diversity of the Polytrichopsida-a review. Bryophyte Diversity and Evolution 43 (1): 98-111. https://doi.org/10.11646/bde.43.1.8

Câmara, P.E.A.S., Carvalho-Silva, M. \& Stech, M. (2021) Antarctic bryophyte research-Current state and future directions. Bryophyte Diversity and Evolution 43 (1): 221-233. https://doi.org/10.11646/bde.43.1.16

Carey, S.B., Kollar, L.M. \& McDaniel, S.F. (2021) Does degeneration or genetic conflict shape gene content on UV sex chromosomes? Bryophyte Diversity and Evolution 43 (1): 133-149.

https://doi.org/10.11646/bde.43.1.11

Dong, S. \& Liu, Y. (2021) The mitochondrial genomes of bryophytes. Bryophyte Diversity and Evolution 43 (1): 112-126. https://doi.org/10.11646/bde.43.1.9

Feldberg, K., Gradstein, S.R., Gröhn, C., Heinrichs, J.†, von Konrat, M., Mamontov, Y.S., Renner, M.A.M., Roth, M., Schäfer-Verwimp, A., Sukkharak, P. \& Schmidt, A.R. (2021) Checklist of fossil liverworts suitable for calibrating phylogenetic reconstructions. Bryophyte Diversity and Evolution 43 (1): 14-71.

https://doi.org/10.11646/bde.43.1.6

Frey, W. \& Stech, M. (2009) Marchantiophyta, Bryophyta, Anthocerotophyta. In: Frey, W. (Ed.) Syllabus of Plant Families. A. Engler's Syllabus der Pflanzenfamilien, 13th ed., Part 3 Bryophytes and seedless Vascular Plants. Borntraeger, Stuttgart, pp. 13-263.

Goffinet, B. \& Shaw, A.J. (2008) Bryophyte Biology, 2nd ed. Cambridge University Press, Cambridge.

Gradstein, S.R. (2021) 50 years of the International Association of Bryologists. Bryophyte Diversity and Evolution 43 (1): 10-13. https://doi.org/10.11646/bde.43.1.5

Hedwig, J. (1801) Species Muscorum Frondosorum, descriptae et tabulis aeneis lxxvii coloratis illustratae. J.A. Barth, Leipzig, 325 pp.

Henry, J.S., Lopez, R.A. \& Renzaglia, K.S. (2020) Differential localization of cell wall polymers across generations in the placenta of Marchantia polymorpha. Journal of Plant Research 133: 911-924. https://doi.org/10.1007/s10265-020-01232-w

Henry, J.S., Ligrone, R., Vaughn, K.C., Lopez, R.A. \& Renzaglia, K.S. (2021) Cell wall polymers in the Phaeoceros placenta reflect developmental and functional differences across generations. Bryophyte Diversity and Evolution 43 (1): 265-283.

https://doi.org/10.11646/bde.43.1.19

Ignatov, M.S. \& Maslova, E.V. (2021) Fossil mosses: what do they tell us about moss evolution? Bryophyte Diversity and Evolution 43 (1): 72-97.

https://doi.org/10.11646/bde.43.1.7

Lewis, L.R., Ickert-Bond, S.M., Biersma, E.M., Convey, P., Goffinet, B., Hassel, K., Kruijer, J.D., La Farge, C., Metzgar, J., Stech, M., Villarreal, J.C. \& McDaniel, S.F. (2017) Future directions and priorities for Arctic bryophyte research. Arctic Science 3: 475-497. https://doi.org/10.1139/AS-2016-0043

Linnaeus, C. (1753) Species Plantarum, vol. 2. Imprensis Laurentii Salvii, Holmiae, pp. 561-1200.

Mitten, W. (1851) A list of all the Mosses and Hepaticae hitherto observed in Sussex. Annals and Magazine of Natural History, series 2, 8: $362-370$.

Ostendorf, A.K., van Gessel, N., Malkowsky, Y., Sabovljevic, M.S., Rensing, S.A., Roth-Nebelsick, A. \& Reski, R. (2021) Polyploidization within the Funariaceae - a key principle behind speciation, sporophyte reduction and the high variance of spore diameters? Bryophyte Diversity and Evolution 43 (1): 164-179. 
https://doi.org/10.11646/bde.43.1.13

Patel, N., Medina, R., Johnson, M. \& Goffinet, B. (2021) Karyotypic diversity and cryptic speciation: Have we vastly underestimated moss species diversity? Bryophyte Diversity and Evolution 43 (1): 150-163.

https://doi.org/10.11646/bde.43.1.12

Patiño, J. \& Vanderpoorten, A. (2021) Island biogeography: an avenue for research in bryology. Bryophyte Diversity and Evolution 43 (1): 206-220.

https://doi.org/10.11646/bde.43.1.15

Patiño, J., Whittaker, R.J., Borges, P.A.V., Fernández-Palacios, J.M., Ah-Peng, C., Araújo, M.B., Ávila, S.P., Cardoso, P., Cornuault, J., de Boer, E.J., de Nascimento, L., Gil, A., González-Castro, A., Gruner, D.S., Heleno, R., Hortal, J., Illera, J.C., Kaiser-Bunbury, C.N., Matthews, T.J., Papadopoulou, A., Pettorelli, N., Price, J.P., Santos, A.M.C., Steinbauer, M.J., Triantis, K.A, Valente, L., Vargas, P., Weigelt, P. \& Emerson, B.C. (2017) A roadmap for island biology: 50 fundamental questions after 50 years of The Theory of Island Biogeography. Journal of Biogeography 44: 963-983.

Pressel, S., Bidartondo, M.I., Field, K.J. \& Duckett, J.G. (2021) Advances in understanding of mycorrhizal-like associations in bryophytes. Bryophyte Diversity and Evolution 43 (1): 284-306.

https://doi.org/10.11646/bde.43.1.20

Proskauer, J. (1951) Studies on Anthocerotales III. 4. The genera Anthoceros and Phaeoceros. Bulletin of the Torrey Botanical Club 78 (4): 331-349.

Sawangproh, W. \& Cronberg, N. (2021) Evidence for interspecific hybridization in bryophytes during pre-molecular and molecular eras. Bryophyte Diversity and Evolution 43 (1): 180-205.

https://doi.org/10.11646/bde.43.1.14

Sousa, A. \& Renner, S.S. (2021) An illustrated step-by-step protocol for investigating liverwort chromosomes. Bryophyte Diversity and Evolution 43 (1): 127-132.

https://doi.org/10.11646/bde.43.1.10

Stanton, D.E. \& Coe, K.K. (2021) 500 million years of charted territory: Functional ecological traits in bryophytes. Bryophyte Diversity and Evolution 43 (1): 234-252.

https://doi.org/10.11646/bde.43.1.17

Vitt, D.H. \& House, M. (2021) Bryophytes as key indicators of ecosystem function and structure of northern peatlands. Bryophyte Diversity and Evolution 43 (1): 253-264.

https://doi.org/10.11646/bde.43.1.18 